19. Rea F, Marulli G, Bortolotti L, Breda C, Favaretto AG, Loreggian L, et al. Induction chemotherapy, extrapleural pneumonectomy (EPP) and adjuvant hemi-thoracic radiation in malignant pleural mesothelioma (MPM): feasibility and results. Lung Cancer. 2007;57:89-95.

20. Weder W, Stahel RA, Bernhard J, Bodis S, Vogt P, Ballabeni P, et al. Multicenter trial of neo-adjuvant chemotherapy followed by extrapleural pneumonectomy in malignant pleural mesothelioma. Ann Oncol. 2007;18:1196-202.

21. Richards WG, Zellos L, Bueno R, Jaklitsch MT, Janne PA, Chirieac LR, et al. Phase I to II study of pleurectomy/decortication and intraoperative intracavitary hyperthermic cisplatin lavage for mesothelioma. J Clin Oncol. 2006;24:1561-7.

22. Weder W, Kestenholz P, Taverna C, Bodis S, Lardinois D, Jerman M, et al. Neoadjuvant chemotherapy followed by extrapleural pneumonectomy in malignant pleural mesothelioma. J Clin Oncol. 2004;22:3451-7.

23. Sugarbaker D, Richards W, Bueno R. Extrapleural pneumonectomy in the treatment of epithelioid malignant pleural mesothelioma. Ann Surg. 2015;260: 577-82.

24. Burt BM, Ali SO, DaSilva MC, Yeap BY, Richards WG, Baldini EH, et al. Clinical indications and results after chest wall resection for recurrent mesothelioma. J Thorac Cardiovasc Surg. 2013;146:1373-9.
25. Yamamuro M, Gerbaudo VH, Gill RR, Jacobson FL, Sugarbaker DJ, Hatabu H. Morphologic and functional imaging of malignant pleural mesothelioma. Eur J Radiol. 2007; 64:356-66.

26. Heelan RT, Rusch VW, Begg CB, Panicek DM, Caravelli JF, Eisen C. Staging of malignant pleural mesothelioma: comparison of CT and MR imaging. Am J Roentgenol. 1999;172:1039-47.

27. Patz EF Jr, Shaffer K, Piwnica-Worms DR, Jochelson M, Sarin M, Sugarbaker DJ, et al. Malignant pleural mesothelioma: value of CT and MR imaging in predicting resectability. Am J Roentgenol. 1992;159:961-6.

28. Stewart D, Waller D, Edwards J, Jeyapalan K, Entwisle J. Is there a role for pre-operative contrast-enhanced magnetic resonance imaging for radical surgery in malignant pleural mesothelioma? Eur J Cardiothorac Surg. 2003;24: 1019-24.

29. Rusch VW, Gill R, Mitchell A, Naidich D, Rice DC, Pass HI, et al. A multicenter study of volumetric computed tomography for staging malignant pleural mesothelioma. Ann Thorac Surg. 2016;102:1059-66.

Key Words: mesothelioma, pleurectomy, pneumonectomy, unresectable
See Article page 2512.

\section{Commentary: Is thoracic cage volume a new parameter for clinical staging in mesothelioma?}

\author{
Marc de Perrot, MD, MSc, FRCSC
}

Macroscopic complete resection (MCR) should be the goal of radical surgery in mesothelioma, independently of whether a pleurectomy-decortication or an extrapleural pneumonectomy is performed. ${ }^{1} \mathrm{MCR}$ is currently achieved in approximately $70 \%$ of patients undergoing surgery for mesothelioma. ${ }^{2}$ Hence, studies to define preoperative indicators that could help reduce the rate of incomplete resection are important.

Diffuse chest wall invasion is a frequent factor precluding MCR. ${ }^{3}$ In addition, it is associated with worse outcome,

\footnotetext{
From the Division of Thoracic Surgery, Toronto General Hospital and Princess Margaret Cancer Centre, University Health Network, Toronto, Ontario, Canada. Disclosures: Author has nothing to disclose with regard to commercial support. Received for publication Dec 16, 2019; revisions received Dec 16, 2019; accepted for publication Dec 17, 2019; available ahead of print Jan 28, 2020.

Address for reprints: Marc de Perrot, MD, MSc, FRCSC, Mesothelioma Program, University Health Network, Toronto General Hospital, 9N-961, 200 Elizabeth St, Toronto, Ontario M5G 2C4, Canada (E-mail: marc.deperrot@uhn.on.ca).

J Thorac Cardiovasc Surg 2020;159:2520-1

$0022-5223 / \$ 36.00$

Copyright (c) 2020 by The American Association for Thoracic Surgery

https://doi.org/10.1016/j.jtcvs.2019.12.048
}

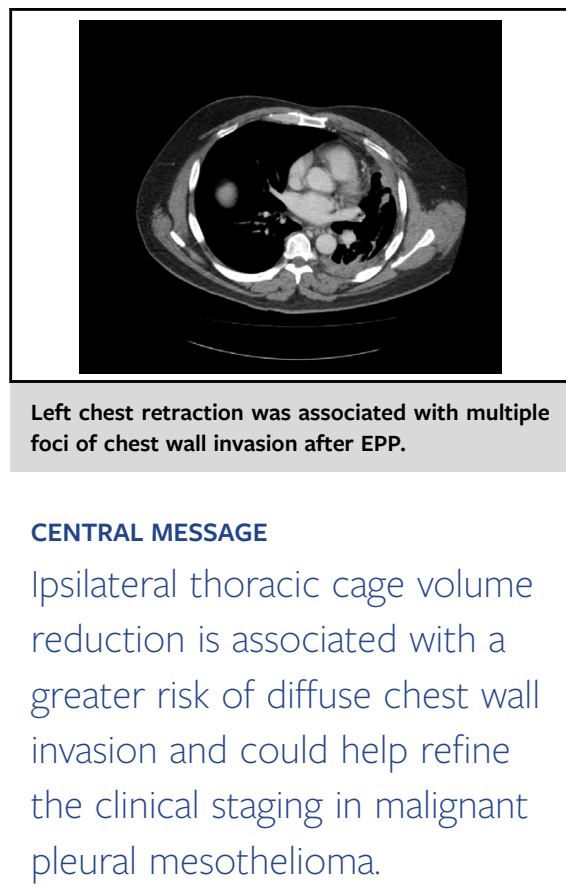

particularly in the presence of chest pain. ${ }^{3,4}$ Better characterization of this parameter preoperatively could therefore be very informative.

The authors observed that diffuse chest wall invasion is more frequent in patients with ipsilateral chest wall retraction. ${ }^{2}$ They, therefore, developed a novel metric based on 3-dimensional thoracic cage volume (TCV) using computed tomography scanning and analyzed the degree 


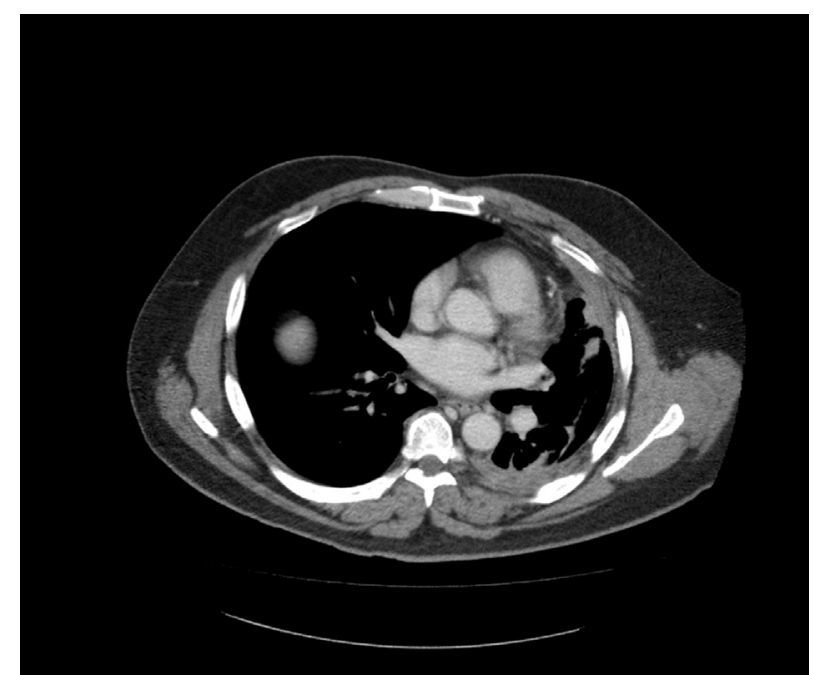

FIGURE 1. Left chest retraction was associated with multiple foci of chest wall invasion after EPP.

of TCV retraction on the affected side compared with the contralateral side.

They defined diffuse chest wall invasion "as an intraoperative finding of tumor invasion through the endothoracic fascia into more than 2 intercostal muscles or ribs and/or multifocal invasion of the chest wall which the surgeon considers to preclude MCR." Although tumor invasion into the endothoracic fascia at the level of 2 or more intercostal spaces would not necessarily preclude MCR, the surgery could carry greater risks and the long-term benefit may be reduced (Figure 1). Hence, preoperative awareness of this factor is potentially beneficial.

The authors demonstrated that reduction in TCV was an independent predictor of diffuse chest wall invasion with potentially better accuracy than magnetic resonance imaging. Noteworthy, chest pain requiring opioids and lower perfusion on ventilation-perfusion scan were also strong predictors of diffuse chest wall invasion, whereas the clinical stage was not. In our experience, both opioid requirement and lung perfusion of less than $20 \%$ in the absence of pleural effusion have been helpful to reduce the rate of exploratory thoracotomy to $0 \%$ in patients undergoing accelerated hemithoracic radiation followed by extrapleural pneumonectomy.

The study reported by Burt and colleagues ${ }^{2}$ has several limitations related to the single-center experience and the retrospective nature of the study. In addition, TCV may not be easily available in the clinic when treatment options are being discussed with the patients. However, this parameter along with tumor volume could provide important radiologic information for the clinical staging. Better clinical staging will help improve patients' selection for surgery and, importantly, provide better parameters to adequately compare surgical and nonsurgical series.

In conclusion, this study is important, as it demonstrates that preoperative radiologic variables can predict intraoperative findings. Although the authors did not assess survival in their study, one would expect that TCV would also have an impact on outcome. Hence, the ipsilateral volume of the thoracic cavity and the tumor volume per se are 2 potential parameters that could help refine the clinical staging of patients with mesothelioma. Hopefully, this will translate into more accurate clinical staging with the next edition of Tumor, Node, Metastasis staging system.

\section{References}

1. Rusch V, Baldini EH, Bueno R, De Perrot M, Flores R, Hasegawa S, et al. The role of surgical cytoreduction in the treatment of malignant pleural mesothelioma: meeting summary of the International Mesothelioma Interest Group Congress, September 11-14, 2012, Boston, Mass. J Thorac Cardiovasc Surg. 2013;145: 909-10.

2. Burt BM, Lee HS, Raghuram AC, Strange C, Mason J, Strange T, et al. Preoperative prediction of unresectability in malignant pleural mesothelioma. J Thorac Cardiovasc Surg. 2020;159:2512-20.e1

3. Nowak AK, Chansky K, Rice DC, Pass HI, Kindler HL, Shemanski L, et al. The IASLC Mesothelioma Staging Project: proposals for revisions of the T Descriptors in the forthcoming Eighth Edition of the TNM Classification for Pleural Mesothelioma. J Thorac Oncol. 2016;11:2089-99.

4. Bottomley A, Coens C, Efficace F, Gaafar R, Manegold C, Burgers S, et al. Symptoms and patient-reported well-being: do they predict survival in malignant pleural mesothelioma? A prognostic factor analysis of EORTC-NCIC 08983: randomized phase III study of cisplatin with or without raltitrexed in patients with malignant pleural mesothelioma. J Clin Oncol. 2007;25:5770-6.

5. de Perrot M, Feld R, Leighl NB, Hope A, Waddell TK, Keshavjee S, et al Accelerated hemithoracic radiation followed by extrapleural pneumonectomy for malignant pleural mesothelioma. J Thorac Cardiovasc Surg. 2016;151: 468-73. 